\title{
The efficacy of a multidisciplinary group program for patients with refractory chronic pain
}

\author{
Masayuki Inoue $\mathrm{PT}^{1,2}$, Shinsuke Inoue $\mathrm{MD}^{2}$, Tatsunori Ikemoto $\mathrm{MD}^{1,2}$, Young-Chang P Arai $\mathrm{MD}^{2}$, Masatoshi Nakata $\mathrm{MD}^{1}$, \\ Atsuko Miyazaki PT², Makoto Nishihara MD², Takashi Kawai MD², Noboru Hatakeyama MD², Setsuko Yamaguchi , \\ Kazuhiro Shimo PT ${ }^{1,2}$, Hirofumi Miyagawa PT ${ }^{1}$, Tomomi Hasegawa ${ }^{1}$, Hiroki Sakurai PT ${ }^{2}$, Yoshinobu Hasegawa PT ${ }^{2}$, \\ Yusuke Ohmichi $\mathrm{PT}^{3}$, Takahiro Ushida $\mathrm{MD}^{1,2}$
}

M Inoue, S Inoue, T Ikemoto, et al. The efficacy of a multidisciplinary group program for patients with refractory chronic pain. Pain Res Manag 2014;19(6):302-308.

BACKGROUND: Chronic pain is a major problem because it can result in not only a reduction in activities of daily living and quality of life but also requires initiation of social assistance. Seeking only to eliminate pain itself would appear to be too narrow an objective, in addition to often being unachievable; therefore, a multifaceted, comprehensive approach with multiple objectives is needed.

OBJECTIVE: To describe the effects of a program (the 'Chronic Pain Class') offering cognitive behavioural therapy to small groups of individuals with refractory chronic pain in Japan. Exercise was an important feature of the program.

METHODS: A total of 46 patients who were experiencing treatment difficulties and decreased activity participated in the program. The programs were conducted in groups of five to seven patients who met weekly for nine weeks. Weekly sessions, which were approximately $2 \mathrm{~h}$ in duration, combined lectures with exercise. Several measures related to pain and physical function were administered at the beginning and the conclusion of the program.

RESULTS: Nine patients dropped out during the program. A number of measures (eg, pain intensity, disability, catastrophizing thoughts) showed significant improvements after intervention $(\mathrm{P}<0.002$ after Bonferroni correction). Furthermore, most measures of physical function showed substantial improvement, especially seated forward bends, zig-zag walking, self-care and 6 min walk test $(\mathrm{P}<0.001)$.

CONCLUSION: The results of the present study provide evidence that a combination of cognitive behavioural therapy and exercise should be recommended to patients with refractory chronic pain.

Key Words: Chronic pain; Cognitive behavioural; Disability; Multidisciplinary; Physical functioning

Chronic pain reduces activities of daily living (ADL) and quality of life (QOL), is a burden not only on the patient but also on family members and others involved, and often severely limits family and social activities. Musculoskeletal pain is also a the major problems in Japan and its aging population because patients require assistance and may become bedridden. A national survey involving 10,000 individuals conducted by a research group from the Ministry of Health, Labour and Welfare revealed that $15.4 \%$ of the population experienced chronic musculoskeletal pain when chronic pain was defined as the presence of symptoms within the past month; persistent pain for at least six months; and a score of $\geq 5$ on a visual analogue scale (VAS) (1). The survey also revealed a high frequency of lumbar, shoulder, neck and knee pain, low satisfaction with treatment and 'doctor shopping' in approximately

\section{L'efficacité d'un programme multidisciplinaire de groupe pour les patients ayant des douleurs chroniques réfractaires}

HISTORIQUE : La douleur chronique est un grave problème, car elle peut non seulement limiter les activités de la vie quotidienne et la qualité de vie, mais également entraîner de besoins d'aide sociale. L'objectif d'éliminer la douleur semblerait trop étroit, sans compter qu'il est souvent irréalisable. C'est pourquoi il faut plutôt adopter une approche polyvalente et détaillée, aux objectifs multiples.

OBJECTIF : Décrire les effets d'un programme (le « cours sur la douleur chronique ») qui propose une thérapie cognitivo-comportementale à de petits groupes de personnes du Japon souffrant de douleurs chroniques réfractaires. L'exercice était une caractéristique importante du programme. MÉTHODOLOGIE : Au total, 46 patients qui éprouvaient des problèmes de traitement et qui faisaient moins d'activité physique qu'auparavant ont participé au programme. Ce programme était offert à des groupes de cinq à sept patients qui se rencontraient une fois par semaine pendant neuf semaines. Les séances hebdomadaires, d'une durée approximative de deux heures chacune, combinaient les conférences et l'exercice. Plusieurs mesures liées à la douleur et à la fonction physique étaient vérifiées au début et à la conclusion du programme.

RÉSULTATS : Neuf patients ont abandonné le programme. Plusieurs mesures (p. ex., intensité de la douleur, invalidité, pensées de catastrophisation) ont beaucoup diminué après l'intervention ( $\mathrm{P}<0,002$ après correction de Bonferroni). De plus, la plupart des mesures de la fonction physique se sont considérablement améliorées, notamment les flexions avant en position assise, la marche en zigzag, les soins personnels et le test de marche de 6 minutes $(P<0,001)$.

CONCLUSION : D'après les résultats de la présente étude, il faudrait recommander une combinaison de thérapie cognitivo-comportementale et d'exercice aux patients souffrant de douleurs chroniques réfractaires.

one-half of the population. The findings suggest that chronic pain, which is often musculoskeletal in nature, not only reduces ADL and QOL, but also raises societal issues. Prolonged pain can result in sleep disorders, daytime sleepiness, decreased arousal, anxiety, depression, lack of appetite and decreased routine activity, occasionally causes withdrawal from society and otherwise disrupts daily activities (2). As a result, patients with chronic pain fall into a 'vicious cycle' in which these psychological and social factors complicate their condition. In these cases, satisfactory treatment outcomes may be unachievable using a uniform therapeutic approach seeking only to eliminate pain. Often, a multifaceted, comprehensive approach is needed (3-5). In particular, therapeutic approaches based on cognitive behavioural therapy under multiple academic disciplines (ie, multidisciplinary) are recommended.

${ }^{1}$ Institute of Physical Fitness, Sports Medicine and Rehabilitation, School of Medicine; ${ }^{2}$ Multidisciplinary Pain Center; ${ }^{3}$ Department of Anatomy, Aichi Medical University, Nagakute, Aichi, Japan

Correspondence: Dr Tatsunori Ikemoto, Institute of Physical Fitness, Sports Medicine and Rehabilitation, School of Medicine, Aichi Medical

University 1-1 Yazako Karimata, Nagakute, Aichi 480-1195, Japan. Telephone 81-561-61-1809, fax 81-561-63-3563,

e-mail tatsunon31-ik@umin.ac.jp / tatsunon31@gmail.com 
Cognitive behavioural therapy seeks to deepen the understanding of one's pain, and teach self-control and coping strategies to encourage behavioural modifications that enable the patient to better confront his or her pain and improve QOL. Treatment using multidisciplinary approaches began in the 1970s at the University of Washington School of Medicine (Seattle, Washington) (6) and was subsequently widely adopted in Western nations. The efficacy of group programs, one component of such approaches, has been widely reported (7,8). It is difficult, however, to conduct group programs profitably under Japan's health insurance system, and few medical institutions have the human resources necessary to operate such programs. Moreover, in Japan, multidisciplinary approaches consisting of cognitive behavioural therapy and exercise for chronic pain have not yet been reported and, therefore, it remains unclear whether these therapeutic strategies are applicable across a range of cultures and not only Western cultures.

In Japan, the Aichi Medical University Multidisciplinary Pain Center and Institute of Physical Fitness, Sports Science and Rehabilitation Center (Nagakute, Japan) began offering group programs for small groups with chronic pain, calling this program the 'Chronic Pain Class'. The program was established in reference to group programs performed in Western nations and has as its motto "Living a positive, active life in spite of pain". The program is an attempt at a multidisciplinary, all-personnel approach, including doctors and support staff, to improve ADL and QOL rather than an approach to directly treat pain. Therefore, in the present study we evaluated multiple outcome measures - not only measures related to pain, but also extensive physical functions. The present article summarizes our findings on the effects of the group program on patients with refractory chronic pain.

Ethics committee

\section{METHODS}

The present study received ethical approval from the Ethics Committee of Aichi Medical University (No.12-067).

\section{Subjects and informed consent}

The present study included 46 participants (19 men and 27 women; mean $[ \pm$ SD] age $65.8 \pm 9.1$ years) in the program and was offered from October 2011 to September 2013 (Table 1). All participants presented at the Pain Center of Aichi Medical University and were encouraged to participate in the program by their attending physician. Most participants were experiencing treatment difficulties and decreased activity or physical strength due to excessive inactivity caused by pain or difficulty dealing with pain. Patients who had experienced prolonged pain for $>6$ months were eligible to be enrolled in the program.

On presentation at the Pain Center, all patients were administered an assessment battery of standardized self-report measures, demographics, symptoms, history and duration of pain. Before consenting to the program, each participant was fully informed by the attending physician of course content, that the coursework would be performed safely, and that all personal information of the participants would be kept confidential.

The mean duration of pain was 8.6 years (range six months to 52 years). A high proportion of the participants had lumbar spinal diseases (eg, spinal canal stenosis, degenerative spondylosis). Twentytwo of the participants (48\%) had undergone surgery of the spine or a leg joint. The most intense pain sites were the back in 19 patients (41\%), legs in 17 patients (37\%), and shoulders, arms and feet in three patients $(7 \%)$ (Table 1$)$.

\section{Program}

All aspects of the program were performed on the fitness floor, in the pool and classrooms of the Institute of Physical Fitness, Sports Science and Rehabilitation of Aichi Medical University. Each group, which consisted of five to seven participants, met weekly (for approximately $2 \mathrm{~h}$ ) for nine weeks. The program combined lectures with exercise. Pain measures and physical function were evaluated at the beginning and conclusion of the program (Table 2).
TABLE 1

Patients' demographic data and characteristics

\begin{tabular}{|c|c|}
\hline Characteristic & $\mathbf{n}$ \\
\hline \multicolumn{2}{|l|}{ Age, years } \\
\hline $31-40$ & 1 \\
\hline $41-50$ & 3 \\
\hline $51-60$ & 6 \\
\hline $61-70$ & 22 \\
\hline $71-80$ & 13 \\
\hline $81-90$ & 1 \\
\hline \multicolumn{2}{|l|}{ Sex, $n / n$} \\
\hline Male/female & $19 / 27$ \\
\hline \multicolumn{2}{|l|}{ Body mass index, $\mathrm{kg} / \mathrm{m}^{2}$} \\
\hline$\leq 20$ & 9 \\
\hline$>20-25$ & 23 \\
\hline$>25$ & 14 \\
\hline \multicolumn{2}{|l|}{ Duration of pain } \\
\hline$>6$ months -1 year & 8 \\
\hline$>1-3$ years & 11 \\
\hline$>3-5$ years & 6 \\
\hline$>5-10$ years & 9 \\
\hline$>10$ years & 12 \\
\hline \multicolumn{2}{|l|}{ Disease type } \\
\hline Lumbar spinal disease & 30 \\
\hline Osteoarthritis & 4 \\
\hline Ossification of posterior longitudinal ligament & 3 \\
\hline Cervical spondylosis & 1 \\
\hline Post-traumatic neck syndrome & 1 \\
\hline Cervical myelopathy & 1 \\
\hline Intramedullary thoracic spinal cord tumour & 1 \\
\hline Spinal arteriovenous fistula & 1 \\
\hline Cerebral infarction & 1 \\
\hline Headache, nonspecific & 1 \\
\hline Genital pain, nonspecific & 1 \\
\hline Coccyalgia, nonspecific & 1 \\
\hline \multicolumn{2}{|l|}{ Chief pain sites } \\
\hline Back to lower back & 19 \\
\hline Legs (thighs, lower legs) & 17 \\
\hline Shoulders and arms & 3 \\
\hline Feet & 3 \\
\hline Neck & 2 \\
\hline Head & 1 \\
\hline Genitals & 1 \\
\hline
\end{tabular}

Before, during and after the program, personnel held conferences to share evaluations and the condition of each of the participants during the program, and to offer guidance under a common mission. At the start of the program, all participants underwent resting electrocardiography to allow a cardiologist to assess program eligibility.

Evaluations: A nurse interviewed each participant during the initial visit to the Pain Center. The interview consisted of questions about the history of the present illness, medical history, treatment and surgical history, social factors (academic background, occupation, income, family composition), lifestyle (exercise, hobbies, amount of spare time) as well as problems among family members, interpersonal relationships at the workplace and dissatisfaction with previous treatments. The interviews were designed to collect as much multifaceted patient information as possible on topics relevant to pain.

The following instruments were used to assess pain: a VAS for pain severity; the Pain Disability Assessment Scale (PDAS) for the degree of impact of pain-related disabilities on lifestyle; the Hospital Anxiety and Depression Scale (HADS) for assessing anxiety and depression (HADS 
TABLE 2

\section{Summary of the group program}

\begin{tabular}{|c|c|c|}
\hline & Contents & Assigned medical personnel \\
\hline \multirow{4}{*}{$\begin{array}{l}\text { Week } 1 \\
(2.5 \mathrm{~h})\end{array}$} & Opening ceremony & Doctor \\
\hline & Assessments (measures of pain) & Doctor \\
\hline & Assessments (physical function) & Physical therapist, trainer, nurse \\
\hline & Floor exercise & Physical therapist \\
\hline \multirow[t]{3}{*}{$\begin{array}{l}\text { Week } 2 \\
(2 \mathrm{~h})\end{array}$} & $\begin{array}{l}\text { Feedback (results of } \\
\text { assessments) }\end{array}$ & Physical therapist \\
\hline & Lecture (theory and treatment) & Doctor \\
\hline & Floor exercise, aerobic exercise & Physical therapist, trainer \\
\hline \multirow[t]{3}{*}{$\begin{array}{l}\text { Week } 3 \\
(2 \mathrm{~h})\end{array}$} & $\begin{array}{l}\text { Lecture (functional anatomy, } \\
\text { tests) }\end{array}$ & Doctor \\
\hline & Floor exercise, aerobic exercise & Physical therapist, trainer \\
\hline & Water aerobics & Physical therapist \\
\hline \multirow[t]{3}{*}{$\begin{array}{l}\text { Week } 4 \\
(2 \mathrm{~h})\end{array}$} & $\begin{array}{l}\text { Lecture (automatic thinking and } \\
\text { pain awareness) }\end{array}$ & Doctor \\
\hline & Floor exercise, aerobic exercise & Physical therapist, trainer \\
\hline & Water aerobics & Physical therapist \\
\hline \multirow[t]{3}{*}{$\begin{array}{l}\text { Week } 5 \\
(2 \mathrm{~h})\end{array}$} & $\begin{array}{l}\text { Lecture (cognitive reconstruction } \\
\text { and sleep) }\end{array}$ & Doctor \\
\hline & Floor exercise, aerobic exercise & Physical therapist, trainer \\
\hline & Water aerobics & Physical therapist \\
\hline \multirow{4}{*}{$\begin{array}{l}\text { Week } 6 \\
(2.5 \mathrm{~h})\end{array}$} & Lecture (dietary habits, nutrition) & Dietician \\
\hline & Group meeting & Doctor \\
\hline & Floor exercise, aerobic exercise & Physical therapist, trainer \\
\hline & Water aerobics & Physical therapist \\
\hline \multirow{3}{*}{$\begin{array}{l}\text { Week } 7 \\
(2 \mathrm{~h})\end{array}$} & Group meeting & Doctor \\
\hline & Floor exercise, aerobic exercise & Physical therapist, trainer \\
\hline & Water aerobics & Physical therapist \\
\hline \multirow{3}{*}{$\begin{array}{l}\text { Week } 8 \\
(2.5 \mathrm{~h})\end{array}$} & Assessments (measures of pain) & Doctor \\
\hline & Assessments (physical function) & Physical therapist, trainer, nurse \\
\hline & Water aerobics & Physical therapist \\
\hline \multirow[t]{3}{*}{$\begin{array}{l}\text { Week } 9 \\
(2 \mathrm{~h})\end{array}$} & $\begin{array}{l}\text { Feedback (results of } \\
\text { assessments) }\end{array}$ & Physical therapist \\
\hline & Home exercise instruction & Physical therapist \\
\hline & Closing ceremony & Doctor \\
\hline
\end{tabular}

Anxiety and HADS Depression); the Pain Catastrophizing Scale (PCS) for measuring catastrophizing due to pain; and the EuroQol 5 Dimension (EQ-5D) for assessing QOL. All of these measures were conducted using Japanese translations (9-13). The authors independently prepared and used a 38-question instrument referred to the 'Pain Test' to characterize patient understanding of lectures and awareness of pain. VAS scores were assessed for the patients in the supine, sitting and standing positions, and when moving. The patients were instructed to indicate, using an arrow, the intensity of pain in each of these positions on a $100 \mathrm{~mm}$ line, with 100 representing the worst pain and zero representing no pain. The PDAS is a scale for measuring lifestyle disabilities of chronic pain patients. Higher scores (on a scale of zero to 60 points) indicate greater degrees of lifestyle disability $(10,14)$. The HADS is a scale for assessing two separate dimensions of anxiety and depression. Again, higher scores (zero to 21 points for anxiety and depression alike) indicate greater degrees of anxiety and depression $(12,15,16)$. The PCS assesses catastrophizing (rumination, magnification and helplessness) about pain, with higher scores (zero to 52 points) indicating greater degrees of catastrophizing $(13,17,18)$. The EQ-5D assesses (on a scale of zero to 1.0 ) the outcome on health-related aspects of QOL (mobility, self-care, usual activities, pain/discomfort and anxiety/depression). Zero indicates death and 1.0 indicates complete health $(11,19)$.

The physical function assessment measured morphology (body weight, body fat percentage); flexibility (seated forward bends); all-body response time; balance (one-legged stand with eyes open); open-eyed, standing stabilometry (hereafter, 'distance of movement from the centre of gravity', 'area of movement from the centre of gravity'); muscular strength: isometric trunk flexion/extension strength, isometric knee flexion/extension strength; walking ability (time of $10 \mathrm{~m}$ zig-zag walk); daily activity ability (standing and sitting ability speed test); self-care ability test; and endurance (6 min walk distance $[6 \mathrm{MD}])$. Body weight and percentage of body fat were calculated with the impedance method using a body fat meter (TBF102 Body Fat Analyzer, Tanita, Japan). Seated forward bends were analyzed by measuring the distance from the fingertips to the toes with the knees fully extended using a seated forward-bend measurement instrument (Takei Scientific Instruments, Japan). The results were expressed as positive numbers when the fingertips passed the toes and as negative numbers when the fingertips did not reach the toes. All-body reaction time was measured with an all-body reaction time meter (TKK 510b, Takei Scientific Instruments). The time from a light signal to jumping by the participant was measured and the mean of five attempts was calculated. For one-legged standing, each participant placed his/her hands on his/her hips, with eyes open, and raised one leg. Only one side was measured for a maximum of $180 \mathrm{~s}$. Open-eyed, standing stabilometry was performed using a stabilometer (Win-Pod, Medicapteur, France). The distance of movement from the centre of gravity and area of movement from the centre of gravity were measured for $30 \mathrm{~s}$ with the participants standing still with their eyes open. Isometric trunk strength (standing) and knee strength (sitting) were measured using a muscle function analyzing and exercising device (Cybex Norm, Cybex International, USA). Maximum $5 \mathrm{~s}$ isometric strength was measured for both flexion and extension. The measurements were divided by body weight to calculate body weight ratios. To measure zig-zag walking, pylons were placed every $2 \mathrm{~m}$ along a $10 \mathrm{~m}$ walking course. The time required to speed walk around the outsides of the pylons and reach the finish line was measured (20). Standing/sitting ability is a measure of the ability to turn over in bed, stand and perform other similar activities. The time required to stand up from a supine position as quickly as possible and then sit down in a chair and stand up again was measured (20). Self-care ability is an overall measure of the ability to change clothing and perform similar activities. The participants were asked to grasp both ends of a length of rope, step across the rope, one leg after the other, while standing, pass the rope from behind them over their head, and return the rope to their front as quickly as possible. The time it took the participants to perform this series of motions was measured three consecutive times (20). For 6MD, the participants walked as far as possible for $6 \mathrm{~min}$ on a flat, $50 \mathrm{~m}$ course at the Institute of Physical Fitness, Sports Science and Rehabilitation, and the distance was measured (21).

Lectures: The lectures covered the theory of pain, functional anatomy, medical imaging examination and treatment for pain, acceptance and cognitive restructuring of pain, how to confront pain, coping skills, sleep, nutrition and control of activities (pacing). Each lecture was conducted by a doctor (orthopedic surgeon, psychiatrist or anesthesiologist), physical therapist or registered dietitian for approximately $30 \mathrm{~min}$. Based on cognitive behavioural therapy, the lectures were designed to inform the participants about how to correct or eliminate excessive fear of pain, improper thinking for treating pain and anxiety caused by distorted cognition, as well as how to control activity levels using appropriate pacing. Group meetings were also held. The participants presented and discussed problems associated with and measures for model scenarios of chronic pain.

Exercise: A doctor (orthopedic surgeon), physiotherapist or trainer offered the participants group exercise sessions that consisted of relaxation, stretching, balance practice, muscle strength exercises and other floor exercises ( $30 \mathrm{~min})$, aerobic exercise with an ergometer $(10 \mathrm{~min})$ and water-based exercise $(30 \mathrm{~min})$. Relaxation consisted of abdominal breathing with the participants laying supine with their eyes closed (22). The participants were instructed to place 


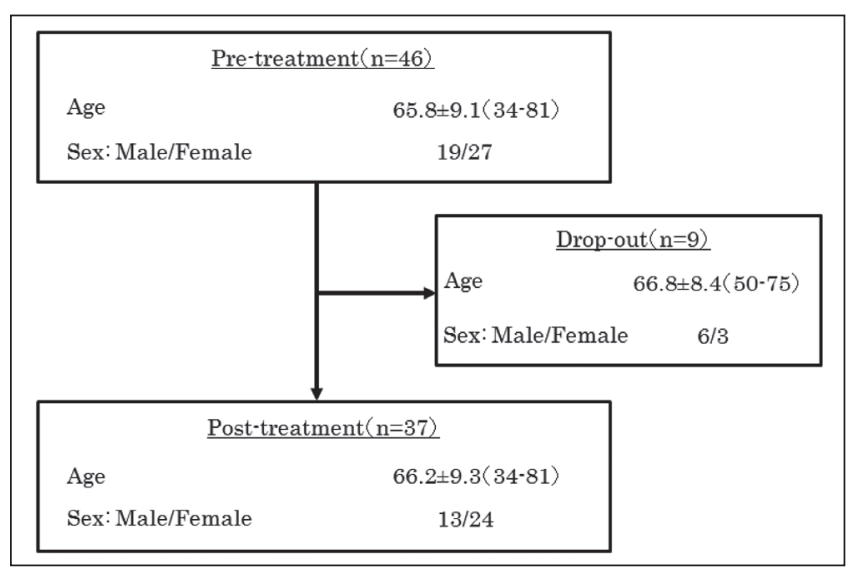

Figure1) Participant distribution. Data presented as mean \pm SD (range) or $n / n$. Nine participants dropped out during the program for specific reasons, while 37 participants completed the program.

their hands on their bellies to confirm that their abdomens were moving. When stretching, the supine participants stretch the muscle groups in their shoulder girdles, lumbar area, hips, thighs and lower legs. Stretching consisted of self-performed static stretching with the muscle groups extended for $20 \mathrm{~s}$ each. Balance practice required the participants to get down on all fours, to raise an arm on one side and the leg on the opposite side and to remain upright on one knee and one hand. The participants engaged in muscular strengthening exercises to strengthen the trunk and leg muscle groups in the supine, sitting and standing positions, performing 10 repetitions under their own body weight. The participants were instructed to perform, at home, a selection of several of the exercises they were capable of completing in $15 \mathrm{~min}$ to $20 \mathrm{~min}$. Exercise instruction was offered in relaxation areas within the facility in as quiet an environment as possible. The participants performed aerobic exercise for $10 \mathrm{~min}$ with an ergometer at a level of nine (very light) to 11 (fairly light) on the Borg Scale of Perceived Exertion, which is a subjective index of exercise strength (23). The load was gradually increased to accommodate the participants. Water aerobics, involving primarily walking as well as relaxation, stretching, muscular strengthening and balance practice, were conducted for $30 \mathrm{~min}$.

\section{Record keeping and rules for participants}

A record chart was given to each participant to enter weekly goals (specific and realistic goals for work, chores, hobbies/leisure activities and exercise), subjective levels of achievement, daily activities, home exercise and other activities. Each participant was also given a pedometer and asked to record the daily number of steps to assess activity levels. To prevent problems among participants as well as isolation, behaviour and language that refuted others or was competitive in any way about pain levels or number of operations was prohibited.

\section{Statistical analysis}

Means and SDs were calculated for all values. The values of each measure before and after the program were analyzed using a paired $t$ test in completed subjects (ie, subjects who completed the study); for subjects who did not complete the study, test parameters at baseline were compared with the completed group using the Mann-Whitney U test for analysis.

A significance level of $\mathrm{P}<0.05$ was used for each outcome; however, multiple measures of outcomes had to be assessed to show the level of improvement of pain burden in completed subjects. Therefore, a Bonferroni-adjusted significance level of 0.002 was calculated to account for the increased possibility of a type I error $(\alpha=0.05)$ for 25 hypothesized predictors. Cohen's d was also used to evaluate the magnitude of the effect size, calculated by standardized
TABLE 3

Changes in pain-related assessments at pretreatment and post-treatment

\begin{tabular}{lcccc}
\hline Variable & Pretreatment & Post-treatment & P & Cohen's d \\
\hline VAS, mm & & & & \\
Supine & $32.0 \pm 25.5$ & $21.2 \pm 23.5$ & 0.004 & 0.473 \\
Sitting & $44.7 \pm 29.1$ & $32.6 \pm 30.5$ & 0.007 & 0.432 \\
Standing & $48.3 \pm 29.6$ & $39.5 \pm 28.9$ & 0.04 & 0.299 \\
Moving & $56.9 \pm 24.7$ & $39.6 \pm 25.2$ & $<0.001^{*}$ & 0.851 \\
PDAS & $25.0 \pm 8.5$ & $19.1 \pm 8.8$ & $<0.001^{*}$ & 0.714 \\
HADS & & & & \\
Anxiety & $7.4 \pm 3.7$ & $6.6 \pm 3.5$ & 0.03 & 0.329 \\
Depression & $8.1 \pm 2.9$ & $6.1 \pm 3.4$ & $<0.001^{*}$ & 0.668 \\
PCS & $32.2 \pm 11.1$ & $25.7 \pm 11.7$ & $<0.001^{*}$ & 0.673 \\
EQ-5D & $0.583 \pm 0.092$ & $0.659 \pm 0.137$ & 0.006 & 0.669 \\
Pain Test & $30.0 \pm 4.5$ & $32.8 \pm 3.4$ & $<0.001^{*}$ & 1.257 \\
\hline
\end{tabular}

Data presented as mean $\pm S D$ unless otherwise indicated. ${ }^{*}$ Denotes statistical significance ( $P<0.002$ after Bonferroni correction). Cohen's d Effect size based on the change score; EQ-5D EuroQol 5 Dimension; HADS Hospital Anxiety and Depression scale; PCS Pain Catastrophizing Scale; PDAS Pain Disability Assessment Scale; VAS Visual Analogue Scale

mean difference, with $g>0.2$ to $0.5=$ small effect size, $g>0.5$ to $0.8=$ medium effect size and $\mathrm{g}>0.8=$ large effect size (24).

\section{RESULTS}

Nine participants dropped out during the program after developing a new disease, experiencing aggravated symptoms or for personal reasons, while 37 participants (13 men and 24 women; mean age $66.2 \pm 9.3$ years) completed the program (Figure 1). Although the EQ-5D score $(\mathrm{P}=0.02)$ tended to be different between the noncompleted group and completed group, none of the parameters showed a significant difference between these two groups at baseline.

As presented in Table 3, a number of measures related to pain assessment showed a significant improvement after intervention $(\mathrm{P}<0.002$ after Bonferroni correction). Pain intensity on moving and PDAS, HADS-Depression, PCS and Pain Test scores showed good to fair improvements with medium-level efficacy or higher (Cohen's $d>0.5$ ).

Furthermore, there were significant improvements in physical function assessments (Table 4). Satisfactory outcomes were observed in seated forward bends (Cohen's $\mathrm{d}=0.75$ ), zig-zag walk (Cohen's $\mathrm{d}=0.60$ ), self-care working ability (Cohen's $\mathrm{d}=1.06$ ) and 6MD (Cohen's $d=0.73$ ). One-legged standing, stabilometry (distance of movement) and muscle strengths did not show a significant improvement or decline.

\section{DISCUSSION}

Cognitive behavioural therapy for chronic pain patients involves the analysis of pain using a cognitive behavioural pain model that pain is not only influenced by its underlying pathophysiology, but also by an individual's cognition, affect and behaviour (25). The efficacy of cognitive behavioural therapy in chronic pain patients has been substantially investigated and reported on by researchers including Eccleston et al (26) and Henschke et al (4), who conducted meta-analyses. However, these strategies for chronic pain were not widely accepted in Japan. In the present study, we demonstrated the efficacy of this program in Japanese society, which has a different culture compared with other countries. Furthermore, the results implied that appropriate exercise combined with cognitive behavioural therapy are more effective for elderly patients than for the age groups studied in previous reports.

Significant improvements from before to after the program were observed in several measures of pain, including the VAS (moving), PDAS, HADS-Depression, PCS and Pain Test. The distorted perception that chronic pain patients have of pain leads to greater fear of pain and reinjury from activity as well as depression, other psychiatric and 
TABLE 4

Changes in physical function before and after treatment

\begin{tabular}{|c|c|c|c|c|}
\hline Variable & Pretreatment & Post-treatment & $\mathbf{P}$ & Cohen's d \\
\hline Weight, kg & $57.8 \pm 11.0$ & $57.4 \pm 11.5$ & 0.02 & 0.333 \\
\hline Body fat, \% & $25.8 \pm 8.7$ & $25.8 \pm 8.9$ & 0.49 & 0.001 \\
\hline Seated forward bends, $\mathrm{cm}$ & $1.9 \pm 12.7$ & $5.0 \pm 11.5$ & $<0.001^{*}$ & 0.750 \\
\hline One-legged stand with eyes open, s & $47.1 \pm 50.1$ & $54.0 \pm 61.7$ & 0.12 & 0.196 \\
\hline \multicolumn{5}{|l|}{ Stabilometry, standing with eyes open } \\
\hline Distance of movement of centre of gravity, $\mathrm{mm}$ & $321.2 \pm 104.6$ & $340.6 \pm 113.2$ & 0.21 & 0.200 \\
\hline \multicolumn{5}{|l|}{ Muscle strength, isometric, $\mathrm{Nm} / \mathrm{kg}$} \\
\hline Knee flexion & $0.48 \pm 0.19$ & $0.46 \pm 0.17$ & 0.21 & 0.166 \\
\hline Knee extension & $1.54 \pm 0.48$ & $1.53 \pm 0.41$ & 0.36 & 0.047 \\
\hline Trunk flexion & $1.23 \pm 0.50$ & $1.27 \pm 0.47$ & 0.24 & 0.115 \\
\hline Trunk extension & $1.65 \pm 0.73$ & $1.66 \pm 0.71$ & 0.47 & 0.021 \\
\hline Zig-zag walking test, s & $9.3 \pm 4.1$ & $8.3 \pm 3.1$ & $<0.001^{\star}$ & 0.593 \\
\hline
\end{tabular}

Data presented as mean $\pm S D$ unless otherwise indicated. *Denotes statistical significance ( $P<0.002$ after Bonferroni correction) Cohen's $d$ Effect size based on the change score

psychological conditions and excessive inactivity. In the present study, 35 (95\%), 17 (46\%) and 23 (62\%) participants exhibited PDAS and HADS anxiety and depression scores above predefined cut-off points (10, eight and eight points, respectively) $(10,16)$, which indicates that many experienced substantial pain-induced disabilities, anxiety and depression. Studies of intervention factors involved with cognitive behavioural therapy for chronic pain patients revealed that improvements in catastrophizing, pain coping skills, confronting pain and attention to pain are important variables for improving disabilities and mood (27-29). Several studies have also investigated the relationship of catastrophizing to pain intensity and degree of disability $(30,31)$ and found that catastrophizing has a greater impact on disability than actual physical function (32). Others found that improvements in catastrophizing precede improvements in disabilities $(33,34)$. Additionally, a significant improvement in scores on the Pain Test, which assessed understanding of the lectures and awareness of pain, indicates that learning coping skills and how to confront pain reduces catastrophizing thoughts and improves disabilities, anxiety and depression. Gradually achieving treatment goals helps patients feel more competent while promoting treatment and preventing recurrence $(35,36)$. The program improved self-efficacy by providing specific, achievable weekly goals, by requiring participants to document their subjective degree of achievement of these goals, and teaching the participants how to achieve their short-term goals without aggravated pain. In the program, these changes in awareness improved QOL by encouraging the participants to increase their activity level, resume hobbies and leisure activities, and actively deepen their relationship with society.

Assessments of physical function revealed significant improvements in seated forward bends, zig-zag walking, self-care ability and 6MD. The increased pain caused by repeated exercise causes chronic pain patients to develop a strong fear of exercise ('kinesiophobia') (37). Excessive inactivity results in decreased activity, often leading to decreased fitness. Muscle tightness and shortening caused by persistent pain as well as joint deformation, postural abnormalities, muscle and soft tissue scarring and fibrosis caused by aging, and other dysfunctions occur concurrently, complicating the state of the patients and triggering new pain. Before this program, many participants had these conditions, thereby exhibiting a marked decrease in physical function (below-average measures for their sex and age). Exercise instruction must involve not only a local approach for the site of pain, but also a whole-body approach including posture and endurance. Additionally, the load applied must be carefully selected to avoid inducing pain during exercise whenever possible. We incorporated low-impact floor exercises (eg, relaxation, stretching, muscle strengthening exercises, balance training), aerobic exercise and water aerobics in the program with a relatively low load level of nine to 11 on the Borg Scale (23).

Seated forward bends assess the flexibility of the lumbar area and backs of the thighs (38). Self-care ability is impacted by the range of shoulder abduction and extension and the extensibility of the lumbar muscle group. The relaxation component of the floor exercises is believed to reduce muscle tightness, and the stretching component is believed to improve muscle blood flow and extensibility of the lumbar muscle group (39), thereby affecting improvements in seated forward bends and self-care ability. Another factor likely to be contributing to the improvement is the extended range of joint motion due to buoyancy and the reduced muscle tightness due to the warm water temperature during water aerobics (40).

Abe et al (41) reported a correlation between zig-zag walking speed and the thickness of the quadriceps and strength of knee extension. The muscle-strengthening exercises of the program were low impact, involving primarily the trunk and legs, with body weight serving as the load on a track or water resistance serving as the load in the water to avoid aggravation of pain. Although the assessments did not reveal an increase in maximal isometric knee or trunk strength, heavy loads ( $\geq 60 \%$ of maximal muscular strength) must be used continuously for at least nine weeks (two to three times per week) to increase the maximum muscular strength of elderly individuals (42). Previous studies have also indicated that, although low-impact muscle-strengthening exercises improved maximal trunk and leg strength, these studies lasted from six months to one or more years (43). Achieving improved maximum muscular strength during the nine-week duration of this program would not have been feasible. However, despite no change in muscle strength of the quadriceps, intervention of the program resulted in an improvement in walking performance in subjects, which may be a result of improvement in psychophysical interaction (eg, improvement in kinesiophobia).

All-body reaction time, a measure of agility, tended to improve. Contributing factors likely include neurological activation (visual information transmission, cerebral information processing) and better contraction rates of trunk and leg muscle groups (44).

In stabilometry, the distance of movement from the centre of gravity indicates the distance moved by the centre of the projected pressure, and the area of movement from the centre of gravity indicates the area moved by the centre of the projected pressure. Although these 
are measures of balance, the distance of movement from the centre of gravity did not significantly change, while the area of movement from the centre of gravity somewhat decreased in this program. This is likely due to the fact that participants began balance practice on a track on all fours, a position that did not cause anxiety about falling, and the position of the practice was gradually shifted to a standing position, thereby avoiding excessive muscle tightness and, as a result, effectively improving balance. Moreover, while in the water, the participants experienced the postures and movements that they could not achieve on a track, thereby improving not only proprioceptors and joint receptors of muscles for maintaining posture but also the function of nerves and muscles through the stimulation of posture-maintaining muscle groups of the trunk, legs and many other organs $(45,46)$. These improvements also may have improved balance. The results of the 6MD test, a simple and convenient measure of respiratory and cardiovascular exercise tolerance, improved by approximately $60 \mathrm{~m}$. Ergometers, which were used in this program, provide better overall cardiorespiratory function and overall endurance as well as the neuromuscular re-education for walking, as evidenced by muscle activation similar to that achieved with walking $(47,48)$. Walking exercise in the water improves cardiorespiratory and fitness function due to water pressure and increased energy expenditure per work performed $(49,50)$, both of which we postulate may have contributed to better $6 \mathrm{MD}$ results.

The program was offered in a group format, which features group dynamics that give participants an incentive to achieve goals and lessen the sense of isolation and alienation. At the beginning of the program, however, some participants were competitive about the degree of their pain and the number of times they had had surgery, and interfered with one another. Such interpersonal problems may result in dropouts. Thus, we implemented rules prohibiting these actions. No participant subsequently dropped out due to interpersonal problems.

Supine and sitting VAS scores indicated signs of improvement and, moreover, moving VAS scores improved significantly, although the approach did not directly address pain itself, as shown in several studies $(51,52)$. The techniques for controlling and managing pain instructed by our lectures improved psychiatric and psychological function, and exercise improved physical function. The features of the

\section{REFERENCES}

1. Nakamura M, Nishiwaki Y, Ushida T, Toyama Y. Prevalence and characteristics of chronic musculoskeletal pain in Japan. J Orthop Sci 2011;16:1-9.

2. Meyer-Rosberg K, Kvarnström A, Kinnman E, Gordh T, Nordfors LO, Kristofferson A. Peripheral neuropathic pain a multidimensional burden for patients. Eur J Pain 2001;5:379-89.

3. Flor H, Fydrich T, Turk DC. Efficacy of multidisciplinary pain treatment centers: A meta-analytic review. Pain 1992;49:221-30.

4. Henschke N, Ostelo RW, van Tulder MW, et al. Behavioural treatment for chronic low-back pain. Cochrane Database Syst Rev 2010;(7):CD002014

5. Inoue $S$, Ushida $T$, Inoue M. Clinical characteristics and multidisciplinary management of chronic musculoskeletal pain. Brain Nerve 2012;64:1287-97. (Japanese)

6. Fordyce WE. Behavioral Methods in Chronic Pain and Illness. St Louis: CV Mosby, 1976.

7. Morley S, Eccleston C, Williams A. Systematic review and meta-analysis of randomized controlled trials of cognitive behaviour therapy and behaviour therapy for chronic pain in adults, excluding headache. Pain 1999;80:1-13

8. Scascighini L, Toma V, Dober-Spielmann S, Sprott H. Multidisciplinary treatment for chronic pain: A systematic review of interventions and outcomes. Rheumatology (Oxford) 2008;47:670-8.

9. Arai YC, Nishihara M, Inoue S, Makino I. Kampo diagnostic procedure, Fuku shin, could be a useful diagnostic tool for psychopathological patients suffering from chronic pain. Evid Based Complement Alternat Med 2013;2013:816216.

10. Arimura T, Komiyama H, Hosoi M. Pain disability assessment scale: A simplified scale for clinical use. Jpn J Behav Ther 1997;23:7-15. (Japanese) group program likely further promoted therapy, thereby alleviating pain as a consequence.

Although we demonstrated that novel features in the 'Chronic Pain Class' based on cognitive behavioural therapy were applicable to Japanese society, there were four major limitations to the present study. First, as described in the 'Subjects' and 'Methods' sections, subjects in the present study were encouraged to participate in the program by their attending physician; therefore, there may have been a selection bias. Second, the multiple measures only applied for patients who agreed to this program without using any subjects as a control; and third, these results are based on a small sample size $(n=37)$. Finally, at the baseline level, although the results did not reveal significant differences in test parameters between completed subjects and noncompleted subjects, the aspect of QOL may be different. This result may indicate that it is more difficult to complete this program for patients with a lower QOL score than for subjects with a high QOL score. Thus, we cannot adequately evaluate the efficacy of 'Chronic Pain Class' according to type of patient with chronic pain. Therefore, we must offer this program to a larger population of patients with refractory chronic pain in future research studies and compare the results against other conventional treatments for chronic pain in Japan.

\section{CONCLUSIONS}

We evaluated the efficacy of a nine-week multidisciplinary group program based on cognitive behavioural therapy for chronic pain patients. Significant improvements in pain intensity on moving, depression, disability, catastrophizing thoughts, flexibility, ADL, walking and endurance following the program suggest that the program was effective.

ACKNOWLEDGEMENTS: This study was performed at the physical fitness centre of Aichi Medical University, and the authors thank all the hardworking staff from the centre. Scientific translation of the manuscript was supported by a Grant-Aid for Scientific Research from the Ministry of Health, Labour and Welfare, Japan.

DISCLOSURES: The authors have no conflicts of interest to declare.
11. Japanese EuroQol Translation Team. The development of the Japanese EuroQol instrument. J Health Care Soc 1997;8:109-23. (Japanese)

12. Kitamura T. The Hospital Anxiety and Depression Scale. Arch Psychiatr Diagn Clin Eval 1993;4:371-2. (Japanese)

13. Matsuoka H, Sakano Y. Assessment of cognitive aspect of pain: Development, reliability, and validation of Japanese version of Pain Catastrophizing Scale. Jpn J Psychosom Med 2007;47:95-102. (Japanese)

14. Yamashiro K, Arimura T, Iwaki R, Jensen MP, Kubo C, Hosoi M. A multidimensional measure of pain interference: Reliability and validity of the pain disability assessment scale. Clin J Pain 2011;27:338-43

15. Matsudaira T, Igarashi $\mathrm{H}$, Kikuchi $\mathrm{H}$, et al. Factor structure of the Hospital Anxiety and Depression Scale in Japanese psychiatric outpatient and student populations. Health Qual Life Outcomes 2009;7:42.

16. Zigmond AS, Snaith RP. The Hospital Anxiety and Depression Scale. Acta Psychiatr Scand 1983;67:361-70.

17. Osman A, Barrios FX, Gutierrez PM, Kopper BA, Merrifield T, Grittmann L. The Pain Catastrophizing Scale: Further psychometric evaluation with adult samples. J Behav Med 2000;23:351-65.

18. Sullivan MJ, Bishop SR. The pain catastrophizing scale. Development and validation. Psychol Assess 1995;7:524-32.

19. Dolan P. Modeling valuations for EuroQol health states. Med Care 1997;35:1095-108.

20. Nagamatsu T, Oida Y, Kitabatake Y, et al. A 6-year cohort study on relationship between functional fitness and impairment of ADL in community-dwelling older persons. J Epidemiol 2003;13:142-8. 
21. ATS Committee on Proficiency Standards for Clinical Pulmonary Function Laboratories. Guidelines for the six-minute walk test. Am J Respir Crit Care Med 2002;166:111-17.

22. Otis JD. Managing Chronic Pain: A Cognitive-Behavioral Therapy Approach. Oxford: Oxford University Press, 2007.

23. Borg GA. Psychophysical bases of perceived exertion. Med Sci Sports Exerc 1982;14:377-81.

24. Cohen J. Statistical Power Analysis for the Behavioral Sciences. Hillsdale: Lawrence Erlbaum Associates, 1988.

25. Keefe FJ. Cognitive behavioral control of arthritis pain. Med Clin North AM 1997;81:277-90.

26. Eccleston C, Williams AC, Morley S. Psychological therapies for the management of chronic pain (excluding headache) in adults. Cochrane Database Syst Rev 2009;CD007407

27. Jensen MP, Turner JA, Romano JM. Changes after multidisciplinary pain treatment in patient pain belief and coping are associated with concurrent changes in patient functioning. Pain 2007;131:38-47.

28. Moss-Morris R, Humphrey K, Johnson MH, Petrie KJ. Patients' perceptions of their pain condition across a multidisciplinary pain management program: Do they change and if so does it matter? Clin J Pain 2007;23:558-64.

29. Wessels T, van Tulder M, Sigl T, Ewert T, Limm H, Stucki G. What predicts outcome in non-operative treatments of chronic low back pain? A systematic review. Eur Spine J 2006 Nov;15:1633-44.

30. Sorbi MJ, Peters ML, Kruise DA, et al. Electronic momentary assessment in chronic pain I: Psychological pain intensity. Clin J Pain 2006;22:55-66.

31. Sorbi MJ, Peters ML, Kruise DA, et al. Electronic momentary assessment in chronic pain II: Pain and psychological pain responses as predictors of pain disability. Clin J Pain 2006;22:67-81.

32. Severeijns R, Vlaeyen JW, van den Hout MA, Weber WE. Pain catastrophizing predicts pain intensity, disability, and psychological distress independent of the level of physical impairment. Clin J Pain 2001;17:165-72.

33. Burns JW, Kubilus A, Bruehl S, Harden RN, Lofland K. Do changes in cognitive factors influence outcome following multidisciplinary treatment for chronic pain? A cross-lagged panel analysis. J Consult Clin Psychol 2003;71:81-91.

34. Spinhoven P, TerKuile M, Kole-Snijders AM, Hutten Mansfeld M, Den Ouden DJ, Vlaeyen JW. Catastrophizing and internal pain control as mediators of outcome in the multidisciplinary treatment of chronic low back pain. Eur J Pain 2004;8:211-9.

35. Bandura A. Self-efficacy: Toward a unifying theory of behavioral change. Psychol Rev 1977;84:191-215.

36. Deci EL, Ryan RM. The support of autonomy and the control of behavior. J Pers Soc Psychol 1987;53:1024-37.
37. Todd D. Kinesiophobia: The relationship between chronic pain and fear-induced disability. Forensic Examiner 1998;7:14-20.

38. Battie MC, Bigos SJ, Fisher LD, et al. The role of spinal flexibility in back pain complaints within industry. Spine 1990;15:768-73.

39. Weppler $\mathrm{CH}$, Magnusson SP. Increasing muscle extensibility: A matter of increasing length or modifying sensation? Phys Ther 2010;90:438-49.

40. Dundar U, Solak O, Yigit I, Evcik D, Kavuncu V. Clinical effectiveness of aquatic exercise to treat chronic low back pain: A randomized controlled trial. Spine 2009;34:1436-40.

41. Abe T, Ogawa M, Loenneke JP, Thiebaud RS, Loftin M, Mitsukawa N. Relationship between site-specific loss of thigh muscle and gait performance in women: The HIREGASAKI study. Arch Gerontol Geriatr 2012;55:e21-5.

42. Campbell WW, Joseph LJ, Davey SL, Cyr-Campbell D, Anderson RA, Evans WJ. Effects of resistance training and chromium picolinate on body composition and skeletal muscle in older men. J Appl Physiol 1999;86:29-39.

43. Yamauchi J, Nakayama S, Ishii N. Effects of bodyweight-based exercise training on muscle functions of leg multi-joint movement in elderly individuals. Geriatr Gerontol Int 2009;9:262-9.

44. Bergmark A. Stability of the lumbar spine. A study in mechanical engineering. Acta Orthop Scand Suppl 1989;230:1-54.

45. Simmons V, Hansen PD. Effectiveness of water exercise on postural mobility in the well elderly: An experimental study on balance enhancement. J Gerontol A Biol Sci Med Sci 1996;51:233-8.

46. Tokuno CD, Carpenter MG, Thorstensson A, Garland SJ, Cresswell AG. Control of the triceps surae during the postural sway of quiet standing. Acta Physiol 2007;3:229-36.

47. Christensen LO, Johannsen P, Sinkjaer T, Petersen N, Pyndt HS, Nielsen JB. Cerebral activation during bicycle movements in man. Exp Brain Res 2000;135:66-72.

48. Ericson MO, Nisell R, Arborelius UP, Ekholm J. Muscular activity during ergometer cycling. Scand J Rehabil Med 1985;17:53-61.

49. Costill DL. Energy requirements during exercise in water. J Sports Med Phys Fitness 1971;11:87-92.

50. Takeshima N, Rogers ME, Watanabe E, et al. Water-based exercise improves health-related aspects of fitness in older women. Med Sci Sports Exerc 2002;34:544-51.

51. Basler HD, Jäkle C, Kröner-Herwig B. Incorporation of cognitivebehavioral treatment into the medical care of chronic low back patients: A controlled randomized study in German pain treatment centers. Patient Educ Couns 1997;31:113-24.

52. Fedoroff IC, Blackwell E, Speed B. Evaluation of group and individual change in a multidisciplinary pain management program. Clin J Pain 2014;30:399-408. 


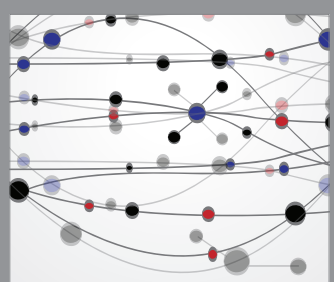

The Scientific World Journal
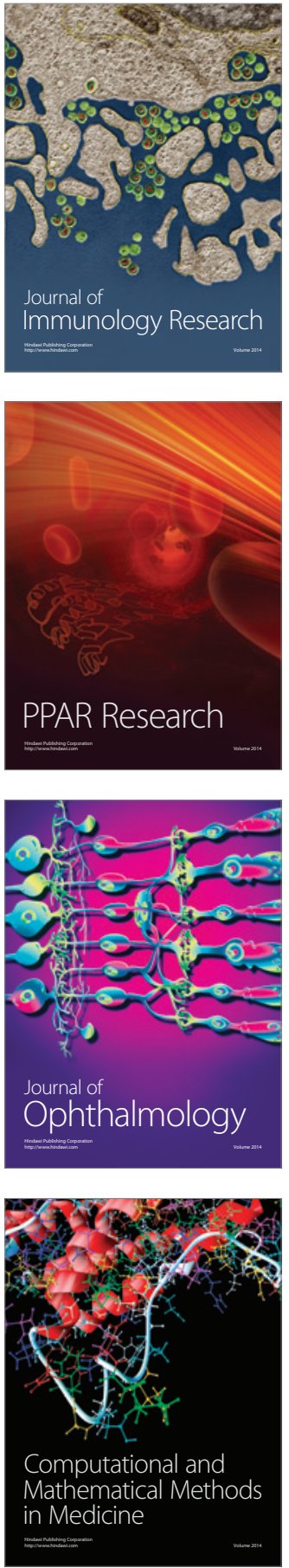

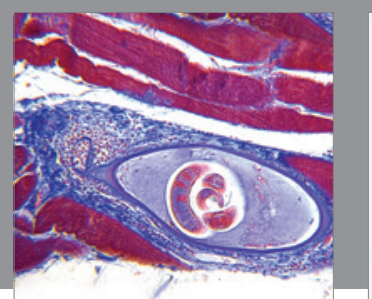

Gastroenterology Research and Practice

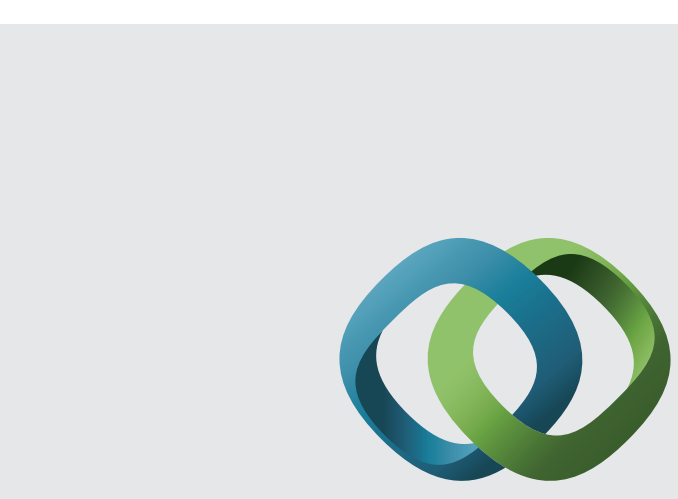

\section{Hindawi}

Submit your manuscripts at

http://www.hindawi.com
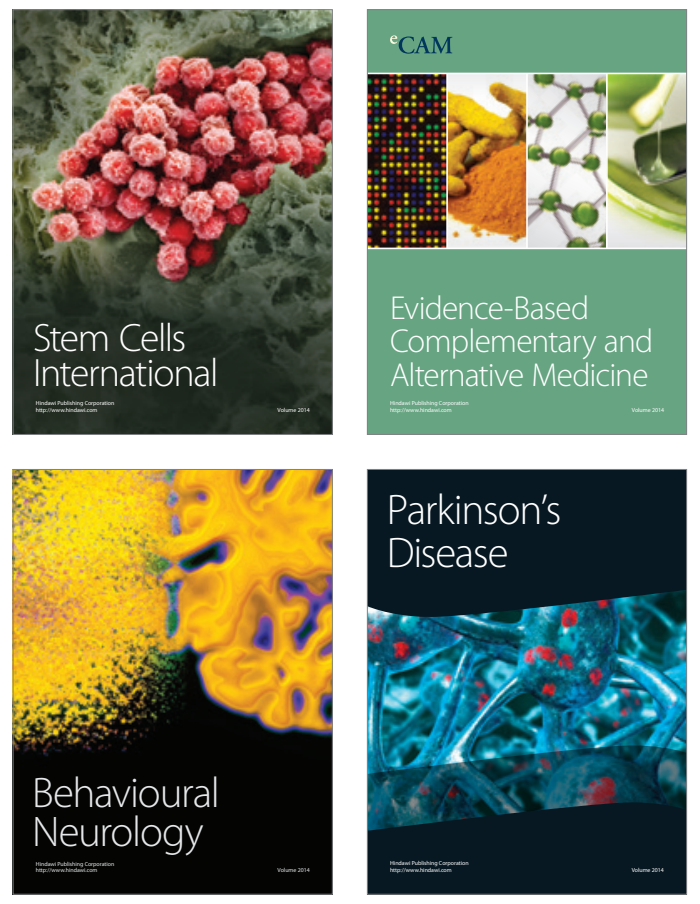
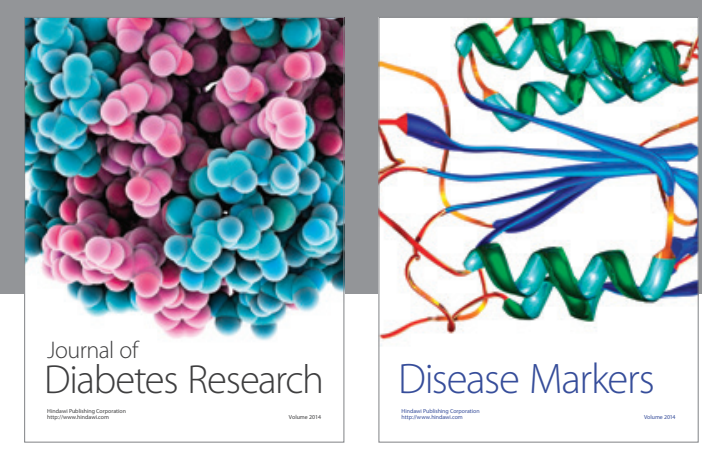

Disease Markers
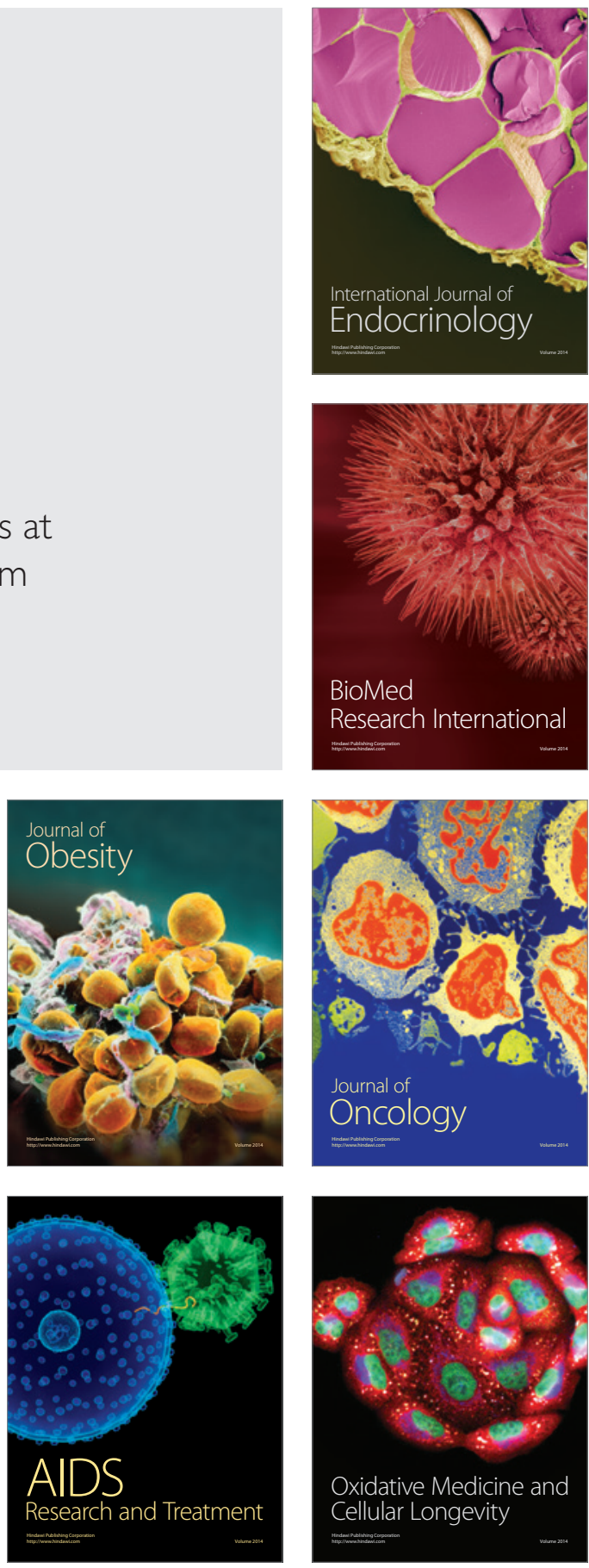